\title{
Multi-Cultural Association of the Serotonin Transporter Gene (SLC6A4) with Substance Use Disorder
}

\author{
Jian Cao', James J Hudziak² and Dawei Li*3,4 \\ 'Department of Pathology, School of Medicine, Yale University, New Haven, CT, USA; ${ }^{2}$ Vermont Center for Children, Youth, and Families, \\ Department of Psychiatry, University of Vermont, Burlington, VT, USA; ${ }^{3}$ Department of Microbiology and Molecular Genetics, University of \\ Vermont, Burlington, VT, USA; ${ }^{4}$ Neuroscience, Behavior, and Health Initiative, University of Vermont, Burlington, VT, USA
}

\begin{abstract}
A number of studies have reported associations between the serotonin transporter gene (SLC6A4) and alcohol, heroin, cocaine, or methamphetamine abuse. Other studies have yielded contrary results. There are a number of reasons for non-replication, including inadequate statistical power, population stratification, and poor phenotype definition. This study was to test the association using a meta-analytic approach across a variety of racial and ethnic populations. Using the genotype data of 55 studies (7999 cases, 8264 controls, and 676 families or parent-offspring trios) published in the past 15 years, we have conducted comprehensive meta-analyses to examine the associations of the 5-HTTLPR and STin2 polymorphisms with substance use disorder. The meta-analyses support the associations of 5-HTTLPR with alcohol, heroin, cocaine, and methamphetamine dependence and abuse (eg, the smallest $P$-values were 0.0058 with odds ratio $(O R)=0.54(0.35,0.84)$; 0.0024 with $O R=0.77(0.66,0.91)$; 0.018 with $O R=1.38(1.06$, I.8I); and 0.028 with $\mathrm{OR}=0.46(0.23,0.92)$ for alcohol, heroin, cocaine, and methamphetamine dependence/abuse, respectively). When all the phenotypes are combined, the $P$-value was 0.0006 with $O R=0.86(0.78,0.94)$ in the combined European, Asian, and Mexican populations and $P$-value was 0.0028 with $O R=1.41(1.13,1.78)$ in the African populations. Evidence of significant associations was also identified in other subgroup analyses regarding differently combined substance and populations. The effect sizes of 5-HTTLPR were comparable among the European, Asian, and Mexican populations, however, the risk allele was more frequent in Asians than in Europeans and Mexicans. The opposite directions of risk allele in African population might be driven by the opposite directions of risk allele in cocaine dependence. This meta-analysis supports that the association of the SLC6A4 gene with substance use disorder varies depending on substances with different risk allele frequencies in the multi-cultural populations. Further studies using larger sample size are warranted.

Neuropsychopharmacology (2013) 38, 1737-1747; doi:10.1038/npp.2013.73; published online 17 April 2013
\end{abstract}

Keywords: meta-analysis; association; serotonin transporter; addiction; common genetic risk

\section{INTRODUCTION}

Alcohol, cocaine, heroin, and methamphetamine addiction constitute major public health issues. The cost of dealing with drug abuse has grown to approximately one trillion dollars per year in the United States (Califano, 2007). An estimated 35.3 million Americans aged 12 years and older reported having used cocaine, and 2.4 million Americans were current users (according to the National Survey on Drug Use and Health). Despite a large amount of research on the etiopathology of substance use disorders, there remains a great deal of work to be done to identify specific genetic and environmental risk factors. Alcohol and drug addictions are familial and share some common genetic factors (Fu et al, 2002; True et al, 1999; Xian et al, 2008).

*Correspondence: Dr D Li, Department of Microbiology and Molecular Genetics, University of Vermont, Burlington, VT 05405, USA, Tel: 802656 9838, E-mail: dawei.li@uvm.edu

Received 27 December 2012; revised 18 March 2013; accepted 19 March 2013; accepted article preview online 21 March 2013
Genetic association studies (Bierut et al, 2007; Edenberg et al, 2010; Zlojutro et al, 2011), eg, Collaborative Study on the Genetics of Alcoholism, have reported that a wide number of candidate genes contribute to the risk for alcoholism and other substance use disorders.

One such gene is the serotonin (5-hydroxytryptamine) transporter gene (SLC6A4 or 5-HTT). SLC6A4 is one of the most studied candidate genes and is the focus of this report. The serotonin transporter protein (SERT) is the presynaptic neuronal reuptake site for serotonin and a site of action for several drugs with central nervous system effects. SERT is a 630 amino-acid protein with 12 transmembrane domains and is a member of the $\mathrm{Na}^{+} / \mathrm{Cl}^{-}$-dependent transporter family (Ramamoorthy et al, 1993). The SLC6A4 gene, spanning 37809 base pairs (bp) and consisting of 14 exons, is located on 17q11.1-q12(Gelernter et al, 1995). SLC6A4 has been linked to alcohol, heroin, cocaine, and methamphetamine dependence and abuse, such as linkage studies (Gelernter et al, 2006; Glatt et al, 2006) have identified the long arm of chromosome 17 as a susceptibility region to heroin dependence. Two important SLC6A4 variable 
number of tandem repeat (VNTR) polymorphisms, 5-HTTLPR and STin2, have been widely studied. The 5 -HTTLPR polymorphism is located in the $5^{\prime}$ regulatory region and the two most common alleles are the 'long' (L) 16-repeat and 'short' (S) 14-repeat alleles (other alleles are observed in various populations (Gelernter et al, 1997)). This variation correlates with differential expression of the SERT protein in cell lines (Lesch et al, 1996). Another VNTR polymorphism, STin2, consists of the presence of a variable number of repeats (usually 9,10 , or 12 repeats) of a $17 \mathrm{bp}$ segment that maps to intron 2 . In vitro studies suggested that the short variants of STin2 decreased promoter activity and further the mRNA and protein concentration, therefore, cell lines carrying short variants showed a decreased serotonin uptake efficiency (Lesch $e t a l$, 1994). Study showed 5-HTTLPR may modulate the gene expression possibly via a combined effect with the STin2 polymorphism (Hranilovic et al, 2004). STin2 and 5-HTTLPR have been also highlighted to be associated with several other disorders, eg, affective disorders (Collier et al, 1996), obsessive-compulsive disorder (McDougle et al, 1998), suicidal behavior (Li and He, 2007), attention-deficit hyperactivity disorder (Gizer et al, 2009), amygdala activation (Munafo et al, 2008; Murphy et al, 2013), stress and depression (Karg et al, 2011), and antidepressant response (Kato and Serretti, 2010).

To date, there have been a number of case-control and family-based association studies that examined the relative risks of one or both of 5-HTTLPR and STin2 in alcohol or drug dependence. Some of these studies reported positive findings (Konishi et al, 2004; Patkar et al, 2001; Wu et al, 2008), but many others found no evidence of association (Supplementary Table 1). There are some reasons for lack of replication, such as insufficient sample size, inadequate statistical power, and failure to control for population variations. The aim of this study was to combine all of the available genotype data from prior case-control and familybased association studies in a multi-cultural meta-analysis of the SLC6A4 5-HTTLPR and STin2 polymorphisms with alcohol and drug (heroin, cocaine, and methamphetamine) abuse in the European, Asian, African, and Mexican populations.

\section{MATERIALS AND METHODS}

\section{Literature Search}

Published reports were selected from Scopus, PubMed, and Chinese Academic Journals database with keywords 'SLC6A4', '5-HTT', 'serotonin transporter', 'association', 'associated', 'drug', 'substance', 'alcoholism', 'alcohol', 'alcoholics', 'heroin', 'cocaine', 'opiate', 'opioid', 'methamphetamine', 'morphine', 'opium' and the specific names or abbreviations of the gene (ie, SERT'). Both English and Chinese keywords were used in searching the Chinese academic journals. All references cited in these studies and in published reviews were examined in order to identify additional works not indexed by the databases. The analyzed data cover all identified English and Chinese publications up to July 2012.

\section{Inclusion Criteria}

Eligible studies had to meet all of the following criteria: they (i) were published in peer-reviewed journals; (ii) contained original and independent data; (ii) presented sufficient samples to calculate the OR with confidence interval (CI) and $P$-value; (iii) were association studies investigating one or two of the polymorphisms using either case-control or family-based approach; (iv) described or referenced appropriate genotyping methods, primers, machines, or protocols; (v) investigated one or more of the following: alcohol, heroin, cocaine, methamphetamine, or more generally drug dependence (two studies (Hallikainen et al, 1999; Shin et al, 2009) included both alcohol dependence subjects and alcohol abusers and one study (Li et al, 2002) included heroin abusers); and (vi) used unrelated individuals with no explicit description of any of these disorders (some studies recruited healthy normal subjects, whereas other studies used random or general population) as controls for case-control study.

\section{Phenotype Inclusion Criteria}

We included studies that diagnosed the patients according to the World Health Organization's International Statistical Classification of Diseases and Related Health Problems (ICD; World Health Organization) or American Psychiatric AssociationDiagnostic and Statistical Manual of Mental Disorder (DSM) system. We also included one study using Michigan Alcoholism Screening Test (Selzer, 1971), one study using Feighner Diagnostic Criteria (Feighner et al, 1972), and one study using Fagerstrom Test for Nicotine Dependence (Heatherton et al, 1991). The procedure of 'extended-quality score' (Li et al, 2006), which scores each paper categorizing it as having 'high', 'median', or 'poor' quality, was applied to assist the assessment of quality of the association studies. Authors were contacted in cases where we determined it would be useful to have additional information regarding their studies.

\section{Statistical Analyses}

Studies were classified according to design as case-control or family-based study, and the latter further subdivided according to statistical methodology into haplotype relative risk (HRR), pedigree disequilibrium test (PDT), and transmission disequilibrium test (TDT). Studies were also subdivided by ethnicity, ie, European ancestries, Asian ancestries, African ancestries, and Mexican ancestries. For studies that contained data from multiple populations, each was considered effectively as an independent study. Data from the case-control, HRR, and PDT studies were summarized by two-by-two tables and TDT studies were summarized by two-by-one tables. The two types of studies were statistically combined by the method described in the previous studies ( $\mathrm{Li}$ and $\mathrm{He}, 2007$; Lohmueller et al, 2003) to join population-based and family-based studies into a single meta-analysis.

From each table a log-OR and its sampling variance were calculated. The Cochran's $\chi^{2}$-based Q statistic test was computed in order to assess heterogeneity to ensure that each group of studies was suitable for meta-analysis. 
Where heterogeneity was found, the random effects model, which yields a wider CI, was adopted; otherwise, the fixed effects model was adopted. Heterogeneity Q tests were also performed for differences in OR between subject ethnicities or phenotypes (eg, Europeans vs Asians or alcohol abuse vs heroin abuse). The Egger's funnel plot asymmetry (Egger et al, 1997) was used to assess evidence for publication bias. The test uses a linear regression approach to measure funnel plot asymmetry on the natural logarithm of the OR. The larger the deviation of each study from the funnel curve, the more pronounced the asymmetry. Results from small studies will scatter widely at the bottom of the graph, with the spread narrowing among larger studies. The significance of the intercept was evaluated using the $T$-test. Begg and Mazumdar rank correlation (Begg and Mazumdar, 1994) was also employed to evaluate potential bias where the $P$-value for Kendall's tau was computed. The 'Duval and Tweedie's Trim and Fill' procedure (Duval and Tweedie, 2000) was adopted to impute the number of potentially missing studies if significant publication bias was found. The Trim and Fill procedure imputes the missing studies, adds them to the analysis, and then re-computes the adjusted overall effect size.

ORs were pooled using the method of DerSimonian and Laird (DerSimonian and Laird, 1986), and 95\% CIs were constructed using Woolf's method (Woolf, 1955). The significance of the overall OR was determined using the $Z$-test. To measure sensitivity of our analysis results, each study was removed in turn from the total, and the remainder then reanalyzed. This procedure was used to ensure that no individual study was entirely responsible for the combined results. Retrospective analysis was performed to better understand the potential effect of the year of publication upon the results. The type I error rate was set at 0.05. The tests were two-tailed. Haplotype construction, counting, and linkage disequilibrium (LD) block defining over a broader genomic region that include SLC6A4 was performed separately using HapMap samples. The multiallelic $\mathrm{D}^{\prime}$ and maximum likelihood haplotype blocks were calculated using the methods described in our previous study (Li et al, 2011). Each ethnic population and each phenotype (alcohol, cocaine, heroin, and methamphetamine dependence and abuse) as well as differently combined sub-groups were analyzed.

\section{RESULTS}

The combined search yielded 2394 references. After discarding overlapping references and those which clearly did not meet the inclusion criteria, 66 studies remained. These studies were then filtered to ensure conformity with the inclusion criteria. Four studies (Foley et al, 2004; Galeeva et al, 2002; Pastorelli et al, 2001) were excluded because no diagnostic criteria was described explicitly; one study (Munafo et al, 2005) because it was investigating social 'drinkers' rather than alcohol-dependent or abusing subjects; one study (Rasmussen et al, 2009) because it investigated alcohol and cigarette consumption rather than dependence or abuse; three studies (Budde et al, 2010; Mingione et al, 2012; Thompson et al, 2010) because no matched control data were described; and two studies
(Wang et al, 2011a; Yang et al, 2012) because the genotype data were same as those in two other studies (Deng et al, 2008; Wang et al, 2011b), respectively. In the end, 55 studies (from 51 references; each of the three references (Gelernter et al, 1998; Kranzler et al, 2002; Nellissery et al, 2003) included two independent ethnic populations, and one reference (Saiz et al, 2009) included data for both alcohol and heroin dependence) composed of 50 case-control studies (Choi et al, 2006; Chu et al, 2010; Deng et al, 2008; Drago et al, 2009; Ezaki et al, 2008; Gelernter et al, 1998; Gelernter et al, 1997; Gerra et al, 2004; Gokturk et al, 2008; Gorwood et al, 2000; Grochans et al, 2011; Hallikainen et al, 1999; Hammoumi et al, 1999; Hong et al, 2003; Ishiguro et al, 1999; Johann et al, 2003; Kohnke et al, 2006; Konishi et al, 2004; Kotler et al, 1999; Kranzler et al, 2002; Lee et al, 2009; Li et al, 2002; Marques et al, 2006; Matsushita et al, 2001; Mokrovic et al, 2008; Namkoong et al, 2008; Nellissery et al, 2003; Parsian and Cloninger, 2001; Patkar et al, 2002; Patkar et al, 2001; Patkar et al, 2004; Philibert et al, 2008; Preuss et al, 2001; Reese et al, 2010; Saiz et al, 2008; Saiz et al, 2009; Sander et al, 1998; Sander et al, 1997; Shin et al, 2009; Stoltenberg et al, 2002; Tan et al, 1999; Thompson et al, 2000; Wang et al, 2012; Wang et al, 2011b; Wu et al, 2008; Yang et al, 2012), three TDT studies (Edenberg et al, 1998; Lichtermann et al, 2000; Samochowiec et al, 2006), one PDT study (Dick et al, 2007), and one HRR study (Hill et al, 2002), met our criteria for inclusion. These studies included 32 studies for European populations (Dick et al, 2007; Drago et al, 2009; Edenberg et al, 1998; Gelernter et al, 1998; Gelernter et al, 1997; Gerra et al, 2004; Gokturk et al, 2008; Gorwood et al, 2000; Grochans et al, 2011; Hallikainen et al, 1999; Hammoumi et al, 1999; Hill et al, 2002; Johann et al, 2003; Kohnke et al, 2006; Kotler et al, 1999; Kranzler et al, 2002; Lichtermann et al, 2000; Marques et al, 2006; Mokrovic et al, 2008; Nellissery et al, 2003; Parsian and Cloninger, 2001; Philibert et al, 2008; Preuss et al, 2001; Reese et al, 2010; Saiz et al, 2008; Saiz et al, 2009; Samochowiec et al, 2006; Sander et al, 1998; Sander et al, 1997; Stoltenberg et al, 2002; Thompson et al, 2000); 16 studies for Asian populations (Choi et al, 2006; Chu et al, 2010; Deng et al, 2008; Ezaki et al, 2008; Hong et al, 2003; Ishiguro et al, 1999; Lee et al, 2009; Li et al, 2002; Matsushita et al, 2001; Namkoong et al, 2008; Shin et al, 2009; Tan et al, 1999; Wang et al, 2012; Wang et al, 2011b; Wu et al, 2008; Yang et al, 2012), 6 studies for African Americans (Gelernter et al, 1998; Kranzler et al, 2002; Nellissery et al, 2003; Patkar et al, 2002; Patkar et al, 2001; Patkar et al, 2004), and 1 for Mexican Americans (Konishi et al, 2004). Among the 55 studies, eight studies (Deng et al, 2008; Gerra et al, 2004; Kotler et al, 1999; Li et al, 2002; Saiz et al, 2008; Saiz et al, 2009; Tan et al, 1999; Yang et al, 2012) investigated heroin dependence or abuse; three studies (Patkar et al, 2002; Patkar et al, 2001; Patkar et al, 2004) investigated cocaine dependence; two studies (Ezaki et al, 2008; Hong et al, 2003) investigated methamphetamine dependence; one study (Chu et al, 2010) investigated nicotine dependence; three studies (Gelernter et al, 1998; Gokturk et al, 2008) investigated alcohol dependence, drug dependence, or both; and the other 38 studies (Choi et al, 2006; Dick et al, 2007; Drago et al, 2009; Edenberg et al, 1998; Gelernter et al, 1997; Gorwood et al, 2000; Grochans 
et al, 2011; Hallikainen et al, 1999; Hammoumi et al, 1999; Hill et al, 2002; Ishiguro et al, 1999; Johann et al, 2003; Kohnke et al, 2006; Konishi et al, 2004; Kranzler et al, 2002; Lee et al, 2009; Lichtermann et al, 2000; Marques et al, 2006; Matsushita et al, 2001; Mokrovic et al, 2008; Namkoong et al, 2008; Nellissery et al, 2003; Parsian and Cloninger, 2001; Philibert et al, 2008; Preuss et al, 2001; Reese et al, 2010; Saiz et al, 2009; Samochowiec et al, 2006; Sander et al, 1998; Sander et al, 1997; Shin et al, 2009; Stoltenberg et al, 2002; Thompson et al, 2000; Wang et al, 2012; Wang et al, 2011b; Wu et al, 2008) investigated alcohol dependence or abuse. Among them, eight studies investigated antisocial alcoholism. For the study by $\mathrm{Wu}$ et al (2008), some new data, unavailable in the published paper, were provided by the authors. These studies included 7999 cases, 8264 controls, and 676 families or parent-offspring trios (Supplementary Table 1). The flow chart of literature search strategy is shown in Figure 1. The results for each polymorphism are detailed below.

\section{5-HTTLPR}

The frequency of the long variant allele (L) varied widely across the populations, high in European normal populations $57 \%(48-71 \%)$ and patients $55 \%(46-67 \%)$, but low in Asian normal populations $27 \%$ (15-71\%) and patients $25 \%$ (17-63\%). Figure 2 shows the average allele frequencies for the four populations. The frequencies were consistent with those observed in our previous study ( $\mathrm{Li}$ and $\mathrm{He}, 2007$ ), in which the L allele were $57 \%$ and $27 \%$ in European and Asian normal populations, respectively. Of the 51 studies included for this polymorphism, 30 studies showed lower frequency in cases than in controls (or less transmissions of the $\mathrm{L}$ allele in families), regardless of ethnicity and sample size (Supplementary Table 2).

Alcohol dependence/abuse. The combined studies of alcohol dependence and abuse showed an overall allelic $P$-value of $0.02(\mathrm{OR}=0.91(0.84,0.99))$ under the random effects model. Evidence of significant association was also

Unique references from PubMed, Scopus,

\& Chinese Academic Journals $(2,394)$

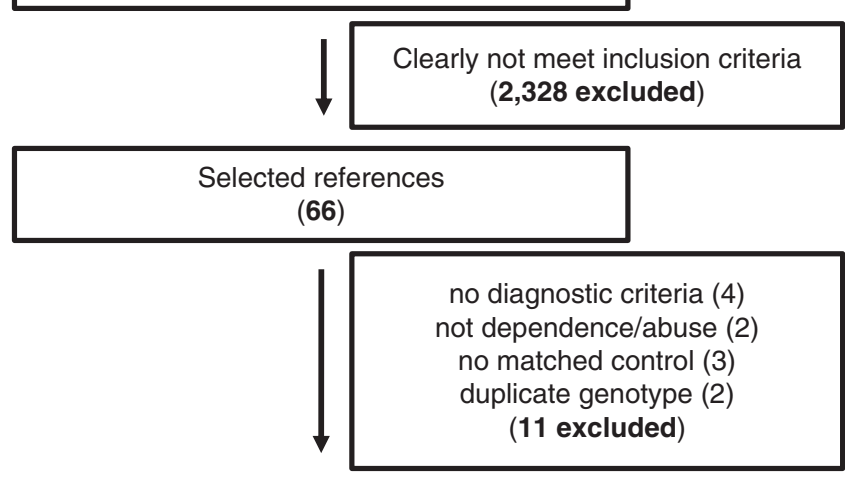

Included studies

(55)

Figure I Flow chart of literature search strategy. found in European $(P=0.048)$ and combined European, Asian, and Mexican populations $(P=0.019)$. The overall $P$-value was still significant $(P=0.037$ and $\mathrm{OR}=0.91(0.84$, $0.99)$ ) after the studies investigating alcohol abusers were excluded from the meta-analysis (only the subjects described as alcohol dependence were analyzed). The dominant model showed evidence of more significant associations, eg, $P=0.009$ and $\mathrm{OR}=0.83(0.72,0.95)$ in the combined European, African, and Mexican populations (Table 1).

We also tested the association between 5-HTTLPR and type II alcoholism with antisocial behavior and the association between 5-HTTLPR and severe alcoholics (eg, in some of the included studies, the patients were described specifically with severe withdrawal symptoms, delirium tremens, and (or) seizure). The meta-analysis showed significant association with severe alcoholics in the combined European and Asian populations $(P=0.007)$ under the dominant model. Significant association was also found in European populations $(P=0.0058)$. However, the metaanalysis of the studies investigating type II alcoholism (or alcoholics) revealed no evidence of significant association.

Heroin dependence/abuse. Significant association was found in the combined studies of heroin dependence and abuse with an allelic $P$-value of 0.02 , which was more significant in European populations with $P=0.0089$ and $\mathrm{OR}=0.82(0.7,0.95)$. The combined studies of heroin dependence revealed more significant results, eg, in the European populations the allelic $P$-value was 0.0009 $(\mathrm{OR}=0.73(0.61,0.88))$, the $P$-values being 0.005 and 0.013 under the recessive and dominant models, respectively (Table 1 ).

Cocaine dependence and methamphetamine dependence. The studies of cocaine dependence and those of methamphetamine dependence only investigated African Americans and Asians, respectively, and the meta-analytic results showed evidence of significant associations with allelic $P$-values of $0.018 \quad(\mathrm{OR}=1.38 \quad(1.06,1.81))$ and 0.04 $(\mathrm{OR}=0.75(0.57,0.99))$, respectively, which were also significant under the recessive model $(\mathrm{ORs}=1.57(1.05,2.35)$ and $0.46(0.23,0.92)$, respectively).

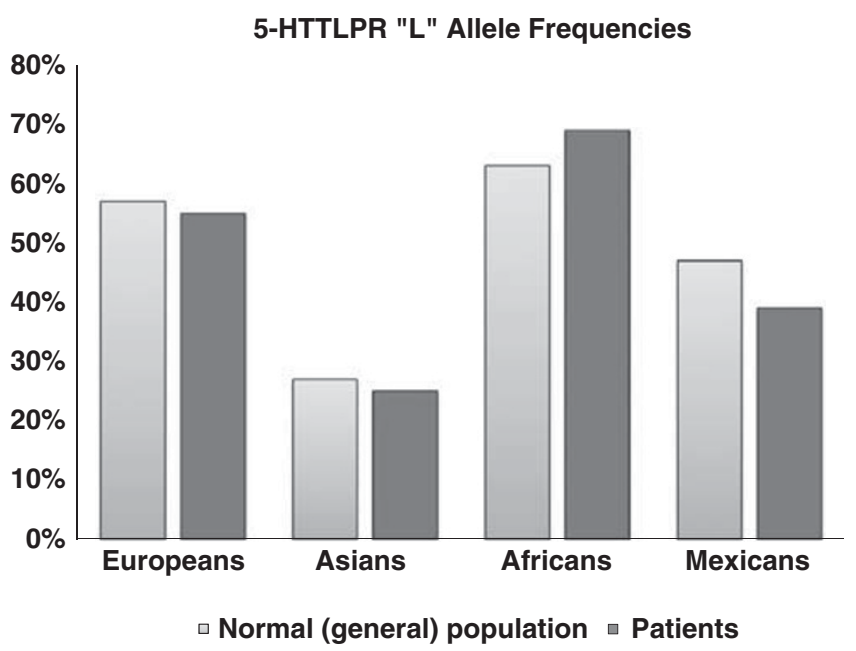

Figure 2 Average allele frequencies of the 5-HTTLPR 'L' allele. 
Table I Results of the Overall and Subgroup Studies for the 5-HTTLPR Polymorphism

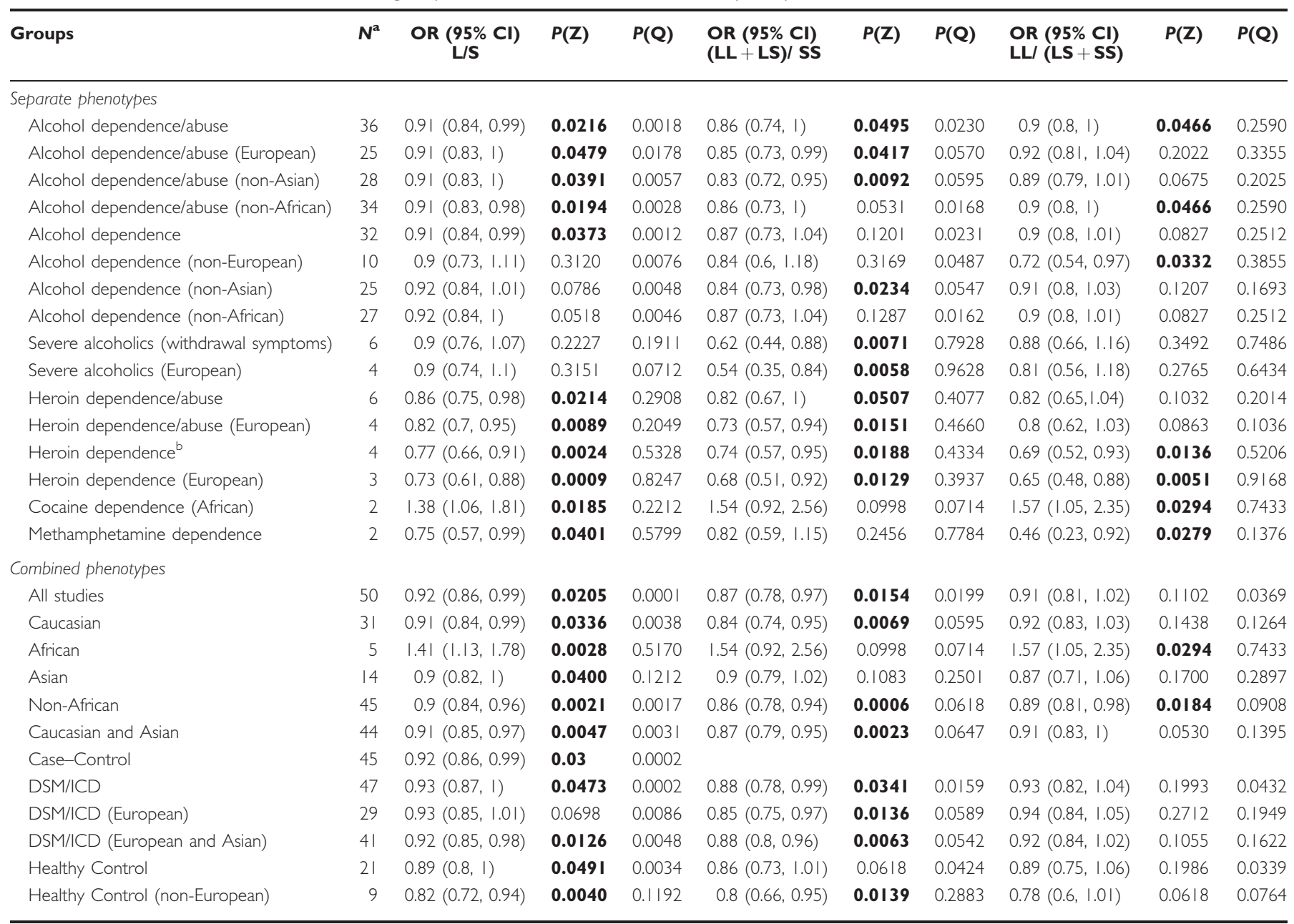

$P(Z): Z$ test used to determine the significance of the overall $O R$. The $P$ values $<0.05$ are indicated in boldfaces.

$P(Q)$ : Cochran's $\chi^{2}$-based $Q$ statistic test used to assess the heterogeneity.

$P(T)$ : $T$ test used to evaluate the significance of publication bias (not shown). $P(T)$ (two-tailed) $>0.1$.

${ }^{a}$ The number of studies included in the analyses.

bAll the samples diagnosed using DSM and the controls were 'Healthy Controls'.

Combined studies. When all the studies of different substance were combined, the allelic analysis showed evidence of significant association (overall $P$-value $=0.02$ and $\mathrm{OR}=0.92(0.86,0.99))$ under the random effects model due to evidence of heterogeneity between studies (Table 1). The meta-analyses also showed associations in each major population, eg, in the combined European $(P=0.03$ and $\mathrm{OR}=0.91(0.84,0.99))$, European and Asian $(P=0.0047$ and $\mathrm{OR}=0.91(0.85,0.97)$ ), and non-African (European, Asian, and Mexican; $P=0.002$ and $\mathrm{OR}=0.9(0.84,0.96))$ populations. The African populations also showed significant with a $P$-value of 0.0028 but in the opposite direction $(\mathrm{OR}=1.41 \quad(1.13,1.78))$. The recessive model (LL $v s$ LS plus SS) also revealed evidence of associations, eg, in the combined non-African $(P=0.018$ and $\mathrm{OR}=0.89$ $(0.81,0.98))$ and African $(P=0.029$ and $\mathrm{OR}=1.57(1.05$, 2.35)) populations. The results under the dominant model (LL plus LS vs SS) showed evidence of stronger association, for example, the overall $P$-value was 0.015 with $\mathrm{OR}$ of $0.87(0.78,0.97)$, and it was more significant in the combined European $(P=0.0069$ and $\mathrm{OR}=0.84 \quad(0.74$, $0.95)$, European and Asian $(P=0.002$ and $\mathrm{OR}=0.87$ $(0.79,0.95))$, and non-African $(P=0.0006$ and $\mathrm{OR}=0.86$ $(0.78,0.94))$ populations.

Diagnosis criteria and control selection. When the studies that employed either the DSM or the ICD system for diagnosis were meta-analyzed, the results showed consistent evidence of significant association. For instance, the combined European and Asian populations showed evidence of significant association with substance use disorders (eg, $P=0.0063$ and $\mathrm{OR}=0.88(0.8,0.96)$ under the dominant model). The control subjects had no explicit description of alcohol or drug dependence or abuse. However, some studies explicitly described their controls as 'healthy' or 'normal' subjects. We also analyzed these 'super controls' separately. Evidence of significant association was also found, eg, the allelic $P$-value was 0.004 $(\mathrm{OR}=0.82(0.72,0.94))$ in the non-European populations. 
Between-group heterogeneity. There was no evidence of significant heterogeneity between Asian studies and European studies, between Asian studies and the others or between Chinese studies and the others, and between each pair of alcohol, heroin, and methamphetamine dependence/abuse for either the allelic or genotypic analyses $(P(\mathrm{Q})>0.1)$. However, heterogeneity was observed for cocaine dependence (Table 2 ), which might be partially due to small sample size (all the subjects were Africans). The forest plots of the 5-HTTLPR polymorphism are shown in Figure 3 and supplementary Figure 1 for the allelic analysis and dominant model, respectively.

\section{STin2 VNTR}

The 10-allele was high in European normal populations $34.6 \%(25-54 \%)$ and patients $35.8 \%(27-46 \%)$, but had an

Table 2 Results of Heterogeneity Estimation Based on Ethnicities and Phenotypes

\begin{tabular}{llcc}
\hline P(Q) values & $\begin{array}{c}\text { Allelic } \\
\text { analysis }\end{array}$ & $\begin{array}{c}\text { Dominant } \\
\text { model }\end{array}$ & $\begin{array}{c}\text { Recessive } \\
\text { model }\end{array}$ \\
\hline Asians vs Europeans & 0.72 & 0.6 & 0.46 \\
Asians vs others & 0.55 & 0.53 & 0.54 \\
Chinese vs others & 0.21 & 0.73 & 0.39 \\
Alcohol vs all drugs & 0.37 & 0.65 & 0.38 \\
Alcohol vs heroin & 0.39 & 0.69 & 0.53 \\
Alcohol vs cocaine & 0.003 & 0.03 & 0.01 \\
Alcohol vs methamphetamine & 0.17 & 0.80 & 0.06 \\
Heroin vs cocaine & 0.002 & 0.02 & 0.01 \\
Heroin vs methamphetamine & 0.40 & I & 0.12 \\
Cocaine vs methamphetamine & 0.002 & 0.04 & 0.003 \\
\hline
\end{tabular}

exceedingly low frequency in Asian normal populations $8 \%$ $(5-10 \%)$ and patients $10 \%(9-15 \%)$, which were consistent with the frequencies that we reported previously (35 and 9\% on average, respectively; $\mathrm{Li}$ and $\mathrm{He}, 2007)$. No evidence of significant association was found for alcohol dependence/ abuse. However, the European studies of heroin dependence and abuse showed week association $(P=0.02$ for the $10 / 12$ genotype). When all the studies of different phenotypes were combined, evidence of significant association was found in the combined Asian populations $(P=0.009$ and $\mathrm{OR}=1.47(1.1,1.95)$ for the 10 -allele and $P=0.02$ and $\mathrm{OR}=0.71(0.54,0.95)$ for the 12 -allele). The results are shown in Supplementary Table 3.

\section{Publication Bias and Fail-safe Analyses}

In the present meta-analysis, no evidence of significant publication bias was found in the meta-analyses of alcohol dependence/abuse, heroin dependence/abuse, combined drugs, or all the combined studies. The $P$-values were $>0.05$ for all these tests based on both Egger's regression intercept and Begg's rank correlation. For the 5-HTTLPR polymorphism, the classic fail-safe analysis showed that at least 38 and 3 assumed nonsignificant association studies would be required to bring the $P$-values to $>0.05$ for alcohol and heroin dependence/abuse, respectively. When the phenotypes were combined, the associations showed stronger: at least 42 and 49 assumed nonsignificant association studies would be required to bring the $P$-values to $>0.05$ for the allelic analysis and dominant model, respectively; for the meta-analysis of non-African (European, Asian, and Mexican) populations at least 114 and 71 assumed nonsignificant studies would be required to bring the $P$-value to $>0.05$ for the allelic analysis and dominant model, respectively. The results further supported the significant associations detected in the meta-analyses.

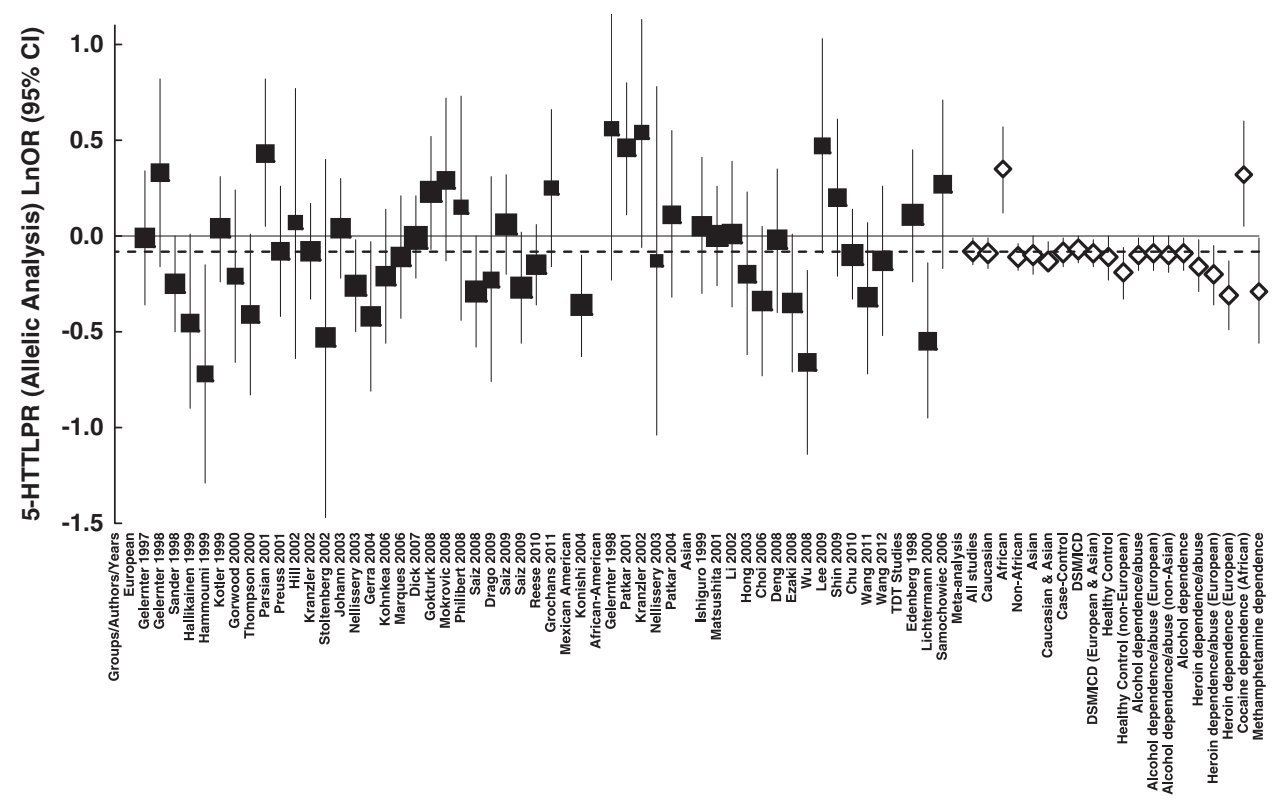

Figure 3 Forest plots of $\ln (\mathrm{OR})$ with $95 \% \mathrm{Cl}$ for the $5-\mathrm{HTTLPR}$ allelic analysis. Black squares indicate the $\ln (\mathrm{OR})$, with the size of the square inversely proportional to its variance, and horizontal lines represent the $95 \% \mathrm{Cls}$. The pooled results are indicated by the unshaded black diamond. For the results of meta-analysis, only the subgroups with $P<0.05$ are shown. 


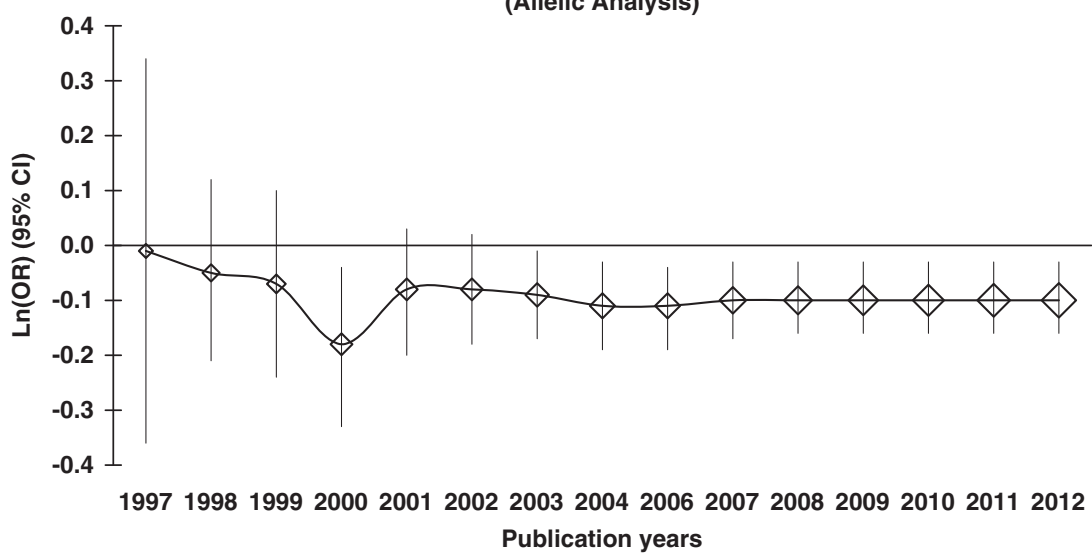

Figure 4 Retrospective analysis for the 5-HTTLPR allelic analysis in non-African populations (combined European, Asian, and Mexican populations). Analysis in retrospect was based on publication year since 1997.

The funnel plots of the 5-HTTLPR studies of alcohol dependence/abuse, heroin dependence/abuse, and combined drugs are shown in Supplementary Figures 2-4, respectively; the plots of the combined studies (combined phenotypes) of the non-African populations are shown for the allelic analysis and dominant model in Supplementary Figures 5 and 6, respectively; the plots of all the combined studies are shown for the allelic analysis and dominant model in Supplementary Figures 7 and 8, respectively.

\section{Sensitivity Analyses}

The results of sensitivity analysis of 5-HTTLPR showed that no individual study included in the meta-analyses biased the significant association of heroin dependence. For instance, the studies of heroin dependence (European populations) showed that the $P$-values were never $>0.0082$ in the allelic analysis, regardless of the data set removed (not shown). Other major findings also showed consistency with the $P$-values $<0.05$. For example, when the phenotypes were combined, the studies of non-African populations showed consistency, regardless of the data set removed, with the $P$-values never $>0.0064$ and never $>0.0062$ for the allelic analysis and dominant model (Supplementary Tables 4 and 5), respectively.

\section{Retrospective Analyses}

The analyses in retrospect of 5-HTTLPR based on publication years showed that the cumulative results, as represented by the asymptote lines on the plots, have tended to be stable since 2006 for the meta-analysis. The plots of the alcohol dependence/abuse are shown for the allelic analysis and dominant model in Supplementary Figures 9 and 10, respectively. For an overall trend, the plots of the combined phenotypes of the European, Asian, and Mexican populations are shown for the allelic analysis and dominant model in Figure 4 and Supplementary Figure 11, respectively.

\section{LD and Haplotype Structure Analyses}

The STin2 polymorphism was in a large haplotype block structure, whereas 5-HTTLPR was located outside of this block, in the gap between this haplotype block and an up-stream block. The plots are shown for the European, Asian, and African populations in Supplementary Figures 12-14, respectively. These structures appears to be consistent with the current results, and implies that the association of 5-HTTLPR may not be due to strong LD with a very close polymorphism. The same findings were observed in two other meta-analysis studies (Fan and Sklar, 2005; $\mathrm{Li}$ and $\mathrm{He}, 2007$ ) dealing with between the two polymorphisms and schizophrenia and suicidal behavior, respectively, although the STin2 polymorphism was shown significant in the study by Fan and Sklar (2005).

\section{DISCUSSION}

Alcohol and drug dependence and abuse are multifactorial disorders, and the genetic contribution to vulnerability to develop the disorders is $40-70 \%$, suggesting a complex inheritance mode in which multiple genes and polymorphisms exert a small effect (Gelernter and Kranzler, 2009; Kendler et al, 2007; Uhl et al, 2008). The meta-analyses found the associations between 5-HTTLPR and alcohol, heroin, cocaine, and methamphetamine dependence and abuse. For example, the smallest $P$-values were 0.0058 with $\mathrm{OR}=0.54(0.35,0.84) ; 0.0024$ with $\mathrm{OR}=0.77(0.66,0.91)$; 0.018 with $\mathrm{OR}=1.38(1.06,1.81)$; and 0.028 with $\mathrm{OR}=0.46$ $(0.23,0.92)$ for alcohol, heroin, cocaine, and methamphetamine dependence/abuse, respectively. When all the phenotypes are combined, the $P$-value was 0.0006 and $\mathrm{OR}$ was $0.86(0.78,0.94)$ in the combined European, Asian, and Mexican populations, whereas $P$ was 0.0028 and OR was $1.41(1.13,1.78)$ in the African populations regarding the ' $L$ ' allele. Evidence of significant association was also observed in additional subgroup analyses regarding differently combined substance and populations. The effect sizes were comparable among the European, Asian, and Mexican populations, however, the risk ' $S$ ' allele was significantly 
more frequent in Asians (73\%) than in Europeans (43\%) and Mexicans (53\%). Based on the between-phenotype heterogeneity analysis, the opposite directions of risk allele of African population vs non-African populations (also explained by ethnic heterogeneity) might be driven by the opposite directions of cocaine dependence $v s$ other substance. The latter could be due to small sample size.

The individual association studies performed by different research groups have contradictory results, the similar phenomenon existing in a previous meta-analysis between SLC6A4 and suicidal behavior (Li and He, 2007). As shown in Figure 2, the 5-HTTLPR allele frequencies vary significantly in different ethnic populations, thus, a difference in sampling methods could differentiate the results. The discrepancy may also be due to insufficient sample size and low statistical power of individual study. In this meta-analysis, the random effects model, which yields larger $P$-values and wider CIs than the fixed effect model, was applied when heterogeneity was found. Evidence of significant association of 5-HTTLPR was identified with alcohol and drug dependence in the overall and subgroup analyses.

Alcohol and drug dependence are often comorbid with psychiatric disorders or behavior problems. For instance, type I alcoholism (Cloninger et al, 1981) was found to have both environmental and genetic risk factors; and type II alcoholism, the severe form of alcoholism, was found to have a more emphasized genetic etiological factor (Sigvardsson et al, 1996). According to Cloninger's neurogenetic tripartite theory of personality, serotonin was hypothesized to be the major neuromodulator of harm avoidance (Cloninger, 1987). However, this meta-analysis found no evidence of significant association of SLC6A4 with antisocial behavior in alcoholism partially because of insufficient data published.

Compared with previous meta-analyses of alcohol dependence (Feinn et al, 2005; McHugh et al, 2010), which included 17 and 22 studies, respectively, mainly from European populations, and reported weak or marginal association (eg, $P=0.03$ ), the present study is a comprehensive meta-analysis combining (and also separately analyzing) alcohol, heroin, cocaine, and methamphetamine dependence and abuse as well as European, Asian, African, and Mexican populations from 55 case-control and familybased studies by using systematic approaches. However, there are some caveats in this study, for example, stress is a major risk factor in addiction and SLC6A4 modulates stress response and emotionality, but there are no stress exposure data available for meta-analysis. For future studies, it may be interesting to investigate other polymorphisms on SLC6A4 or nearby genes (eg, BLMH), including the noncoding regions as those polymorphisms may influence the gene functions according to the Encyclopedia of DNA Elements (ENCODE) project (Bernstein et al, 2012).

As the first association report between this polymorphism and affective disorders (Collier et al, 1996), 5-HTTLPR has been widely studied with a great number of neuropsychiatric disorders. The SLC6A4 gene protein transports the neurotransmitter serotonin from synaptic spaces into presynaptic neurons. 5-HTTLPR is a noncoding polymorphism that impacts its gene transcription. Various findings support that 5-HTTLPR has important role in the pathogenesis and/or etiology of brain diseases and psychiatric disorders.
For example, 5-HTTLPR affects the rate of serotonin uptake and might influence gray matter in anterior cingulate brain region (Pezawas et al, 2005); and the short ' $S$ ' allele might drive amygdala hyper-reactivity (Hariri et al, 2005). Because of the fundamental roles, 5-HTTLPR is expected to have 'pleiotropy effect', ie, a same mutation allele affects multiplerelated diseases and traits.

To conclude, our meta-analysis using existing genotype data supports that the association of SLC6A4 5-HTTLPR varies depending on substances (alcohol, heroin, cocaine, and methamphetamine). The ' $\mathrm{S}$ ' allele was the risk allele in the European, Asian, and Mexican populations, whereas the ' $\mathrm{L}$ ' allele was the risk allele in the African populations. The effect sizes were comparable in the European, Asian, and Mexican populations, but the risk ' $S$ ' allele was more frequent in Asians than Europeans or Mexicans. The opposite directions of the African populations might be driven by the opposite directions of cocaine dependence. Further studies using larger sample size are warranted.

\section{Electronic-database information}

Accession Numbers and URLs for data in this article are as follows:

GenBank, http://www.ncbi.nlm.nih.gov/Genbank/ for genomic structure of SLC6A4;

Online Mendelian Inheritance in Man (OMIM), http:// www.ncbi.nlm.nih.gov/Omim for SLC6A4;

Genotype data, http://www.hapmap.org/ for SLC6A4;

Genome data, http://genome.ucsc.edu/ for SLC6A4.

\section{ACKNOWLEDGEMENTS}

This work was supported by the start-up fund from the University of Vermont, and by the research grants DA12849, DA12690, AA017535, AA12870, RC2DA028909, DA030976, and AA11330 from the National Institutes of Health, USA. We thank the authors who provided the data related to their individual association studies for this metaanalysis, in particular, $\mathrm{Dr} \mathrm{Ru}-\mathrm{Band} \mathrm{Lu}$, who provided the data related to their original studies for our study. We thank Drs Joel Gelernter and Hongyu Zhao for their revisions and comments on the manuscript. We also thank the anonymous reviewers for very helpful comments to improve the manuscript.

\section{DISCLOSURE}

The authors declare no conflict of interest.

\section{REFERENCES}

American Psychiatric Association Diagnostic and Statistical Manual of Mental Disorders (DSM). American Psychiatric Press: Washington, DC.

Begg CB, Mazumdar M (1994). Operating characteristics of a rank correlation test for publication bias. Biometrics 50: 1088-1101.

Bernstein BE, Birney E, Dunham I, Green ED, Gunter C, Snyder M (2012). An integrated encyclopedia of DNA elements in the human genome. Nature 489: 57-74.

Bierut LJ, Madden PA, Breslau N, Johnson EO, Hatsukami D, Pomerleau OF et al (2007). Novel genes identified in a 
high-density genome wide association study for nicotine dependence. Hum Mol Genet 16: 24-35.

Budde H, Sander T, Wernicke C, Muller A, Gallinat J, Schmidt LG et al (2010). Serotonin transporter promoter polymorphism and dopaminergic sensitivity in alcoholics. J Neural Transm 117: 133-138.

Califano JA (2007). High Society: How Substance Abuse Ravages America and What to Do About It Public Affairs. Public Affairs Press: NY, USA.

Choi IG, Kee BS, Son HG, Ham BJ, Yang BH, Kim SH et al (2006). Genetic polymorphisms of alcohol and aldehyde dehydrogenase, dopamine and serotonin transporters in familial and nonfamilial alcoholism. Eur Neuropsychopharmacol 16: 123-128.

Chu C, Zhang L, Yang Y (2010). Association of polymorphism in the serotonin transporter promote gene with smoking behaviors in Chinese males. Chin J Drug Depend 19: 196-200.

Cloninger CR (1987). Neurogenetic adaptive mechanisms in alcoholism. Science 236: 410-416.

Cloninger CR, Bohman M, Sigvardsson S (1981). Inheritance of alcohol abuse. Cross-fostering analysis of adopted men. Arch Gen Psychiatry 38: 861-868.

Collier DA, Stober G, Li T, Heils A, Catalano M, Di Bella D et al (1996). A novel functional polymorphism within the promoter of the serotonin transporter gene: possible role in susceptibility to affective disorders. Mol Psychiatry 1: 453-460.

Deng D, Li J, Xu X, Zhang R, Zhang B, Duan C et al (2008). Association of heroin dependence with polymorphisms in the serotonin transporter promote gene. Chin J Drug Depend 17: 176-178.

DerSimonian R, Laird N (1986). Meta-analysis in clinical trials. Control Clin Trials 7: 177-188.

Dick DM, Plunkett J, Hamlin D, Nurnberger J Jr, Kuperman S, Schuckit M et al (2007). Association analyses of the serotonin transporter gene with lifetime depression and alcohol dependence in the Collaborative Study on the Genetics of Alcoholism (COGA) sample. Psychiatr Genet 17: 35-38.

Drago A, Liappas I, Petio C, Albani D, Forloni G, Malitas P et al (2009). Epistasis between IL1A, IL1B, TNF, HTR2A, 5-HTTLPR and TPH2 variations does not impact alcohol dependence disorder features. Int J Environ Res Public Health 6: 1980-1990.

Duval S, Tweedie R (2000). Trim and fill: a simple funnel-plotbased method of testing and adjusting for publication bias in meta-analysis. Biometrics 56: 455-463.

Edenberg HJ, Koller DL, Xuei X, Wetherill L, McClintick JN, Almasy L et al (2010). Genome-wide association study of alcohol dependence implicates a region on chromosome 11. Alcohol Clin Exp Res 34: 840-852.

Edenberg HJ, Reynolds J, Koller DL, Begleiter H, Bucholz KK, Conneally PM et al (1998). A family-based analysis of whether the functional promoter alleles of the serotonin transporter gene HTT affect the risk for alcohol dependence. Alcohol Clin Exp Res 22: $1080-1085$.

Egger M, Davey Smith G, Schneider M, Minder C (1997). Bias in metaanalysis detected by a simple, graphical test. BMJ 315: 629-634.

Ezaki N, Nakamura K, Sekine Y, Thanseem I, Anitha A, Iwata Y et al (2008). Short allele of 5-HTTLPR as a risk factor for the development of psychosis in Japanese methamphetamine abusers. Ann N Y Acad Sci 1139: 49-56.

Fan JB, Sklar P (2005). Meta-analysis reveals association between serotonin transporter gene STin2 VNTR polymorphism and schizophrenia. Mol Psychiatry 10: 928-938 891.

Feighner JP, Robins E, Guze SB, Woodruff RA Jr., Winokur G, Munoz R (1972). Diagnostic criteria for use in psychiatric research. Arch Gen Psychiatry 26: 57-63.

Feinn R, Nellissery M, Kranzler HR (2005). Meta-analysis of the association of a functional serotonin transporter promoter polymorphism with alcohol dependence. Am J Med Genet B Neuropsychiatr Genet 133B: 79-84.

Foley PF, Loh EW, Innes DJ, Williams SM, Tannenberg AE, Harper CG et al (2004). Association studies of neurotransmitter gene polymorphisms in alcoholic Caucasians. Ann N Y Acad Sci 1025: $39-46$.

Fu Q, Heath AC, Bucholz KK, Nelson E, Goldberg J, Lyons MJ et al (2002). Shared genetic risk of major depression, alcohol dependence, and marijuana dependence: contribution of antisocial personality disorder in men. Arch Gen Psychiatry 59: 1125-1132.

Galeeva AR, Gareeva AE, Iur'ev EB, Khusnutdinova EK (2002). [VNTR polymorphisms of the serotonin transporter and dopamine transporter genes in male opiate addicts]. Mol Biol (Mosk) 36: 593-598.

Gelernter J, Kranzler H, Coccaro EF, Siever LJ, New AS (1998). Serotonin transporter protein gene polymorphism and personality measures in African American and European American subjects. Am J Psychiatry 155: 1332-1338.

Gelernter J, Kranzler H, Cubells JF (1997). Serotonin transporter protein (SLC6A4) allele and haplotype frequencies and linkage disequilibria in African- and European-American and Japanese populations and in alcohol-dependent subjects. Hum Genet 101: 243-246.

Gelernter J, Kranzler HR (2009). Genetics of alcohol dependence. Hum Genet 126: 91-99.

Gelernter J, Pakstis AJ, Kidd KK (1995). Linkage mapping of serotonin transporter protein gene SLC6A4 on chromosome 17. Hum Genet 95: 677-680.

Gelernter J, Panhuysen C, Wilcox M, Hesselbrock V, Rounsaville B, Poling J et al (2006). Genomewide linkage scan for opioid dependence and related traits. Am J Hum Genet 78: 759-769.

Gerra G, Garofano L, Santoro G, Bosari S, Pellegrini C, Zaimovic A et al (2004). Association between low-activity serotonin transporter genotype and heroin dependence: behavioral and personality correlates. Am J Med Genet B Neuropsychiatr Genet 126B: 37-42.

Gizer IR, Ficks C, Waldman ID (2009). Candidate gene studies of ADHD: a meta-analytic review. Hum Genet 126: 51-90.

Glatt SJ, Su JA, Zhu SC, Zhang R, Zhang B, Li J et al (2006). Genome-wide linkage analysis of heroin dependence in Han Chinese: results from wave one of a multi-stage study. Am J Med Genet B Neuropsychiatr Genet 141B: 648-652.

Gokturk C, Schultze S, Nilsson KW, von Knorring L, Oreland L, Hallman J (2008). Serotonin transporter (5-HTTLPR) and monoamine oxidase (MAOA) promoter polymorphisms in women with severe alcoholism. Arch Womens Ment Health 11: 347-355.

Gorwood P, Batel P, Ades J, Hamon M, Boni C (2000). Serotonin transporter gene polymorphisms, alcoholism, and suicidal behavior. Biol Psychiatry 48: 259-264.

Grochans E, Grzywacz A, Malecka I, Samochowiec A, Karakiewicz B, Samochowiec J (2011). [Research on associations between selected polymorphisms of genes DRD2, 5HTT, GRIK3, ADH4 and alcohol dependence syndrome]. Psychiatr Pol 45: 325-335.

Hallikainen T, Saito T, Lachman HM, Volavka J, Pohjalainen T, Ryynanen OP et al (1999). Association between low activity serotonin transporter promoter genotype and early onset alcoholism with habitual impulsive violent behavior. $\mathrm{Mol}$ Psychiatry 4: 385-388.

Hammoumi S, Payen A, Favre JD, Balmes JL, Benard JY, Husson M et al (1999). Does the short variant of the serotonin transporter linked polymorphic region constitute a marker of alcohol dependence? Alcohol 17: 107-112.

Hariri AR, Drabant EM, Munoz KE, Kolachana BS, Mattay VS, Egan MF et al (2005). A susceptibility gene for affective disorders and the response of the human amygdala. Arch Gen Psychiatry 62: $146-152$.

Heatherton TF, Kozlowski LT, Frecker RC, Fagerstrom KO (1991). The Fagerstrom Test for Nicotine Dependence: a revision of the Fagerstrom Tolerance Questionnaire. Br J Addict 86: 1119-1127.

Hill EM, Stoltenberg SF, Bullard KH, Li S, Zucker RA, Burmeister M (2002). Antisocial alcoholism and serotonin-related polymorphisms: association tests. Psychiatr Genet 12: 143-153. 
Hong CJ, Cheng CY, Shu LR, Yang CY, Tsai SJ (2003). Association study of the dopamine and serotonin transporter genetic polymorphisms and methamphetamine abuse in Chinese males. J Neural Transm 110: 345-351.

Hranilovic D, Stefulj J, Schwab S, Borrmann-Hassenbach M, Albus M, Jernej B et al (2004). Serotonin transporter promoter and intron 2 polymorphisms: relationship between allelic variants and gene expression. Biol Psychiatry 55: 1090-1094.

Ishiguro H, Saito T, Akazawa S, Mitushio H, Tada K, Enomoto M et al (1999). Association between drinking-related antisocial behavior and a polymorphism in the serotonin transporter gene in a Japanese population. Alcohol Clin Exp Res 23: 1281-1284.

Johann M, Bobbe G, Putzhammer A, Wodarz N (2003). Comorbidity of alcohol dependence with attention-deficit hyperactivity disorder: differences in phenotype with increased severity of the substance disorder, but not in genotype (serotonin transporter and 5-hydroxytryptamine-2c receptor). Alcohol Clin Exp Res 27: 1527-1534.

Karg K, Burmeister M, Shedden K, Sen S (2011). The serotonin transporter promoter variant (5-HTTLPR), stress, and depression meta-analysis revisited: evidence of genetic moderation. Arch Gen Psychiatry 68: 444-454.

Kato M, Serretti A (2010). Review and meta-analysis of antidepressant pharmacogenetic findings in major depressive disorder. Mol Psychiatry 15: 473-500.

Kendler KS, Myers J, Prescott CA (2007). Specificity of genetic and environmental risk factors for symptoms of cannabis, cocaine, alcohol, caffeine, and nicotine dependence. Arch Gen Psychiatry 64: 1313-1320.

Kohnke MD, Kolb W, Lutz U, Maurer S, Batra A (2006). The serotonin transporter promotor polymorphism 5-HTTLPR is not associated with alcoholism or severe forms of alcohol withdrawal in a German sample. Psychiatr Genet 16: 227-228.

Konishi T, Luo HR, Calvillo M, Mayo MS, Lin KM, Wan YJ (2004). $\mathrm{ADH}_{1}{ }^{\star} 1, \mathrm{ADH} 1 \mathrm{C}^{\star} 2, \mathrm{DRD} 2(-141 \mathrm{C}$ Ins), and 5-HTTLPR are associated with alcoholism in Mexican American men living in Los Angeles. Alcohol Clin Exp Res 28: 1145-1152.

Kotler M, Cohen H, Kremer I, Mel H, Horowitz R, Ohel N et al (1999). No association between the serotonin transporter promoter region (5-HTTLPR) and the dopamine D3 receptor (BalI D3DR) polymorphisms and heroin addiction. Mol Psychiatry 4: 313-314.

Kranzler H, Lappalainen J, Nellissery M, Gelernter J (2002). Association study of alcoholism subtypes with a functional promoter polymorphism in the serotonin transporter protein gene. Alcohol Clin Exp Res 26: 1330-1335.

Lee YS, Choi SW, Han DH, Kim DJ, Joe KH (2009). Clinical manifestation of alcohol withdrawal symptoms related to genetic polymorphisms of two serotonin receptors and serotonin transporter. Eur Addict Res 15: 39-46.

Lesch KP, Balling U, Gross J, Strauss K, Wolozin BL, Murphy DL et al (1994). Organization of the human serotonin transporter gene. J Neural Transm Gen Sect 95: 157-162.

Lesch KP, Bengel D, Heils A, Sabol SZ, Greenberg BD, Petri S et al (1996). Association of anxiety-related traits with a polymorphism in the serotonin transporter gene regulatory region. Science 274: 1527-1531.

Li D, Collier DA, He L (2006). Meta-analysis shows strong positive association of the neuregulin 1 (NRG1) gene with schizophrenia. Hum Mol Genet 15: 1995-2002.

Li D, He L (2007). Meta-analysis supports association between serotonin transporter (5-HTT) and suicidal behavior. Mol Psychiatry 12: 47-54.

Li D, Zhao H, Gelernter J (2011). Strong association of the alcohol dehydrogenase $1 \mathrm{~B}$ gene $(\mathrm{ADH} 1 \mathrm{~B})$ with alcohol dependence and alcohol-induced medical diseases. Biol Psychiatry 70: 504-512.

Li T, Liu X, Zhao J, Hu X, Ball DM, Loh el W et al (2002). Allelic association analysis of the dopamine D2, D3, 5-HT2A, and
GABA(A)gamma2 receptors and serotonin transporter genes with heroin abuse in Chinese subjects. Am J Med Genet 114: 329-335.

Lichtermann D, Hranilovic D, Trixler M, Franke P, Jernej B, Delmo CD et al (2000). Support for allelic association of a polymorphic site in the promoter region of the serotonin transporter gene with risk for alcohol dependence. Am J Psychiatry 157: 2045-2047.

Lohmueller KE, Pearce CL, Pike M, Lander ES, Hirschhorn JN (2003). Meta-analysis of genetic association studies supports a contribution of common variants to susceptibility to common disease. Nat Genet 33: 177-182.

Marques FZ, Hutz MH, Bau CH (2006). Influence of the serotonin transporter gene on comorbid disorders among alcohol-dependent individuals. Psychiatr Genet 16: 125-131.

Matsushita S, Yoshino A, Murayama M, Kimura M, Muramatsu T, Higuchi S (2001). Association study of serotonin transporter gene regulatory region polymorphism and alcoholism. Am J Med Genet 105: 446-450.

McDougle CJ, Epperson CN, Price LH, Gelernter J (1998). Evidence for linkage disequilibrium between serotonin transporter protein gene (SLC6A4) and obsessive compulsive disorder. Mol Psychiatry 3: 270-273.

McHugh RK, Hofmann SG, Asnaani A, Sawyer AT, Otto MW (2010). The serotonin transporter gene and risk for alcohol dependence: a meta-analytic review. Drug Alcohol Depend 108: 1-6.

Mingione CJ, Heffner JL, Blom TJ, Anthenelli RM (2012). Childhood adversity, serotonin transporter (5-HTTLPR) genotype, and risk for cigarette smoking and nicotine dependence in alcohol dependent adults. Drug Alcohol Depend 123: 201-206.

Mokrovic G, Matosic A, Hranilovic D, Stefulj J, Novokmet M, Oreskovic D et al (2008). Alcohol dependence and polymorphisms of serotonin-related genes: association studies. Coll Antropol 32(Suppl 1): 127-131.

Munafo MR, Brown SM, Hariri AR (2008). Serotonin transporter (5-HTTLPR) genotype and amygdala activation: a meta-analysis. Biol Psychiatry 63: 852-857.

Munafo MR, Lingford-Hughes AR, Johnstone EC, Walton RT (2005). Association between the serotonin transporter gene and alcohol consumption in social drinkers. Am J Med Genet B Neuropsychiatr Genet 135B: 10-14.

Murphy SE, Norbury R, Godlewska BR, Cowen PJ, Mannie ZM, Harmer CJ et al (2013). The effect of the serotonin transporter polymorphism (5-HTTLPR) on amygdala function: a metaanalysis. Mol Psychiatry 18: 512-520.

Namkoong K, Cheon KA, Kim JW, Jun JY, Lee JY (2008). Association study of dopamine D2, D4 receptor gene, GABAA receptor beta subunit gene, serotonin transporter gene polymorphism with children of alcoholics in Korea: a preliminary study. Alcohol 42: 77-81.

Nellissery M, Feinn RS, Covault J, Gelernter J, Anton RF, Pettinati $\mathrm{H}$ et al (2003). Alleles of a functional serotonin transporter promoter polymorphism are associated with major depression in alcoholics. Alcohol Clin Exp Res 27: 1402-1408.

Parsian A, Cloninger CR (2001). Serotonergic pathway genes and subtypes of alcoholism: association studies. Psychiatr Genet 11: 89-94.

Pastorelli R, Bardazzi G, Saieva C, Cerri A, Gestri D, Allamani A et al (2001). Genetic determinants of alcohol addiction and metabolism: a survey in Italy. Alcohol Clin Exp Res 25: 221-227.

Patkar AA, Berrettini WH, Hoehe M, Hill KP, Gottheil E, Thornton CC et al (2002). No association between polymorphisms in the serotonin transporter gene and susceptibility to cocaine dependence among African-American individuals. Psychiatr Genet 12: 161-164.

Patkar AA, Berrettini WH, Hoehe M, Hill KP, Sterling RC, Gottheil E et al (2001). Serotonin transporter (5-HTT) gene polymorphisms and susceptibility to cocaine dependence among AfricanAmerican individuals. Addict Biol 6: 337-345. 
Patkar AA, Berrettini WH, Mannelli P, Gopalakrishnan R, Hoehe MR, Bilal L et al (2004). Relationship between serotonin transporter gene polymorphisms and platelet serotonin transporter sites among African-American cocaine-dependent individuals and healthy volunteers. Psychiatr Genet 14: 25-32.

Pezawas L, Meyer-Lindenberg A, Drabant EM, Verchinski BA, Munoz KE, Kolachana BS et al (2005). 5-HTTLPR polymorphism impacts human cingulate-amygdala interactions: a genetic susceptibility mechanism for depression. Nat Neurosci 8: 828-834.

Philibert RA, Sandhu H, Hollenbeck N, Gunter T, Adams W, Madan A (2008). The relationship of 5HTT (SLC6A4) methylation and genotype on mRNA expression and liability to major depression and alcohol dependence in subjects from the Iowa Adoption Studies. Am J Med Genet B Neuropsychiatr Genet 147B: 543-549.

Preuss UW, Koller G, Soyka M, Bondy B (2001). Association between suicide attempts and 5-HTTLPR-S-allele in alcoholdependent and control subjects: further evidence from a German alcohol-dependent inpatient sample. Biol Psychiatry 50: 636-639.

Ramamoorthy S, Bauman AL, Moore KR, Han H, Yang-Feng T, Chang AS et al (1993). Antidepressant- and cocaine-sensitive human serotonin transporter: molecular cloning, expression, and chromosomal localization. Proc Natl Acad Sci USA 90: 2542-2546.

Rasmussen H, Bagger Y, Tanko LB, Christiansen C, Werge T (2009). Lack of association of the serotonin transporter gene promoter region polymorphism, 5-HTTLPR, including rs25531 with cigarette smoking and alcohol consumption. Am J Med Genet B Neuropsychiatr Genet 150B: 575-580.

Reese J, Kraschewski A, Anghelescu I, Winterer G, Schmidt LG, Gallinat J et al (2010). Haplotypes of dopamine and serotonin transporter genes are associated with antisocial personality disorder in alcoholics. Psychiatr Genet 20: 140-152.

Saiz PA, Garcia-Portilla MP, Arango C, Morales B, MartinezBarrondo S, Alvarez C et al (2008). Association between heroin dependence and 5-HT2A receptor gene polymorphisms. Eur Addict Res 14: 47-52.

Saiz PA, Garcia-Portilla MP, Florez G, Arango C, Corcoran P, Morales B et al (2009). Differential role of serotonergic polymorphisms in alcohol and heroin dependence. Prog Neuropsychopharmacol Biol Psychiatry 33: 695-700.

Samochowiec J, Kucharska-Mazur J, Grzywacz A, Jablonski M, Rommelspacher H, Samochowiec A et al (2006). Family-based and case-control study of DRD2, DAT, 5HTT, COMT genes polymorphisms in alcohol dependence. Neurosci Lett 410: 1-5.

Sander T, Harms H, Dufeu P, Kuhn S, Hoehe M, Lesch KP et al (1998). Serotonin transporter gene variants in alcohol-dependent subjects with dissocial personality disorder. Biol Psychiatry 43: 908-912.

Sander T, Harms H, Lesch KP, Dufeu P, Kuhn S, Hoehe M et al (1997). Association analysis of a regulatory variation of the serotonin transporter gene with severe alcohol dependence. Alcohol Clin Exp Res 21: 1356-1359.

Selzer ML (1971). The Michigan alcoholism screening test: the quest for a new diagnostic instrument. Am J Psychiatry 127: $1653-1658$.

Shin S, Stewart R, Ferri CP, Kim JM, Shin IS, Kim SW et al (2009). An investigation of associations between alcohol use disorder and polymorphisms on ALDH2, BDNF, 5-HTTLPR, and MTHFR genes in older Korean men. Int J Geriatr Psychiatry 25: 441-448.

Sigvardsson S, Bohman M, Cloninger CR (1996). Replication of the Stockholm Adoption Study of alcoholism. Confirmatory crossfostering analysis. Arch Gen Psychiatry 53: 681-687.
Stoltenberg SF, Twitchell GR, Hanna GL, Cook EH, Fitzgerald HE, Zucker RA et al (2002). Serotonin transporter promoter polymorphism, peripheral indexes of serotonin function, and personality measures in families with alcoholism. Am J Med Genet 114: 230-234.

Tan EC, Yeo BK, Ho BK, Tay AH, Tan CH (1999). Evidence for an association between heroin dependence and a VNTR polymorphism at the serotonin transporter locus. Mol Psychiatry 4: 215-217.

Thompson MD, Gonzalez N, Nguyen T, Comings DE, George SR, O'Dowd BF (2000). Serotonin transporter gene polymorphisms in alcohol dependence. Alcohol 22: 61-67.

Thompson RD, Heffner JL, Strong JA, Blom TJ, Anthenelli RM (2010). Relationship between the serotonin transporter polymorphism and obsessive-compulsive alcohol craving in alcoholdependent adults: a pilot study. Alcohol 44: 401-406.

True WR, Xian H, Scherrer JF, Madden PA, Bucholz KK, Heath AC et al (1999). Common genetic vulnerability for nicotine and alcohol dependence in men. Arch Gen Psychiatry 56: $655-661$.

Uhl GR, Drgon T, Johnson C, Li CY, Contoreggi C, Hess J et al (2008). Molecular genetics of addiction and related heritable phenotypes: genome-wide association approaches identify 'connectivity constellation' and drug target genes with pleiotropic effects. Ann N Y Acad Sci 1141: 318-381.

Wang TY, Lee SY, Chen SL, Chang YH, Chen SH, Chu CH et al (2012). Interaction between serotonin transporter and serotonin receptor $1 \mathrm{~B}$ genes polymorphisms may be associated with antisocial alcoholism. Behav Brain Funct 8: 18 .

Wang X, Zhong S, Gao L, Dou S, He G, Ran Y et al (2011a). An association study between polymorphism of alcohol dehydrogenase (ADH1B), aldehyde dehydrogenase (ALDH2), cytochrome (CYP4502E1), Catechol-O-Methyltransferase (COMT) and 5-hydroxytryptamine transporter (5-HTT) genes in Yunnan Han population with alcohol dependence. Afr J Biotechnol 10: 12164-12170.

Wang XJ, Zhong SR, Bao JJ, Dou SJ, Wu WY, Jing Q (2011b). [Association of polymorphism in the serotonin transporter gene promote with the susceptibility to alcohol dependence in Yunnan Han Population]. Yi Chuan 33: 48-53.

Woolf B (1955). On estimating the relation between blood group and disease. Ann Hum Genet 19: 251-253.

World Health Organization. World Health Organization's International Statistical Classification of Diseases and Related Health Problems (ICD). WHO: Geneva.

Wu CY, Wu YS, Lee JF, Huang SY, Yu L, Ko HC et al (2008). The association between DRD2/ANKK1, 5-HTTLPR gene, and specific personality trait on antisocial alcoholism among Han Chinese in Taiwan. Am J Med Genet B Neuropsychiatr Genet 147B: 447-453.

Xian H, Scherrer JF, Grant JD, Eisen SA, True WR, Jacob T et al (2008). Genetic and environmental contributions to nicotine, alcohol and cannabis dependence in male twins. Addiction 103: $1391-1398$

Yang M, Kavi V, Wang W, Wu Z, Hao W (2012). The association of 5-HTR2A-1438A/G, COMTVal158Met, MAOA-LPR, DATVNTR and 5-HTTVNTR gene polymorphisms and antisocial personality disorder in male heroin-dependent Chinese subjects. Prog Neuropsychopharmacol Biol Psychiatry 36: 282-289.

Zlojutro M, Manz N, Rangaswamy M, Xuei X, Flury-Wetherill L, Koller D et al (2011). Genome-wide association study of theta band event-related oscillations identifies serotonin receptor gene HTR7 influencing risk of alcohol dependence. Am J Med Genet B Neuropsychiatr Genet 156B: 44-58.

Supplementary Information accompanies the paper on the Neuropsychopharmacology website (http://www.nature.com/npp) 